Saul Michael (Orcid ID: 0000-0002-4916-8619)

Shpigler Hagai (Orcid ID: 0000-0003-1369-4112)

\title{
Honey bee neurogenomic responses to affiliative and agonistic social interactions
}

Hagai Y. Shpigler ${ }^{1}$, Michael C. Saul ${ }^{1}$, Emma E. Murdoch ${ }^{1}$, Frida Corona ${ }^{1}$, Amy C. CashAhmed $^{1}$, Christopher H. Seward ${ }^{1,2}$, Sriram Chandrasekaran ${ }^{3}$, Lisa J. Stubbs ${ }^{1,2,4}$ and Gene E. Robinson $^{1,4,5}$

1. Carl R. Woese Institute for Genomic Biology, University of Illinois at UrbanaChampaign (UIUC), Urbana, IL, USA

2. Department of Cell and Developmental Biology, UIUC, Urbana, IL, USA

3. Department of Biomedical Engineering, University of Michigan, g, MI, USA

4. Neuroscience Program, UIUC, Urbana, IL, USA

5. Department of Entomology, UIUC, Urbana, IL, USA

Corresponding author:

Gene E. Robinson: generobi@,illinois.edu

\section{Keywords:}

Social behavior; Affiliative behavior; Biological embedding; Honey Bee; Alloparental care; Mushroom bodies; Transcriptomic; RNA-seq; Transcriptional Regulatory Network; Epigenetics; ChIP-seq.

This is the author manuscript accepted for publication and has undergone full peer review but has not been through the copyediting, typesetting, pagination and proofreading process, which may lead to differences between this version and the Version of Record. Please cite this article as doi: $10.1111 / \mathrm{gbb} .12509$

This article is protected by copyright. All rights reserved. 
Abstract:

Social interactions can be divided into two categories, affiliative and agonistic. How neurogenomic responses reflect these opposing valences is a central question in the biological embedding of experience. To address this question, we exposed honey bees to a queen larva, which evokes nursing, an affiliative alloparenting interaction, and measured the transcriptomic response of the mushroom body brain region at different times after exposure. Hundreds of genes were differentially expressed at distinct time points, revealing a dynamic temporal patterning of the response. Comparing these results to our previously published research on agonistic aggressive interactions, we found both shared and unique transcriptomic responses to each interaction. The commonly responding gene set was enriched for nuclear receptor signaling, the set specific to nursing was enriched for olfaction and neuron differentiation, and the set enriched for aggression was enriched for cytoskeleton, metabolism, and chromosome organization. Whole brain histone profiling after the affiliative interaction revealed few changes in chromatin accessibility, suggesting that the transcriptomic changes derive from already accessible areas of the genome. Although only one stimulus of each type was studied, we suggest that elements of the observed transcriptomic responses reflect molecular encoding of stimulus valence, thus priming individuals for future encounters. This hypothesis is supported by behavioral analyses showing that bees responding to either the affiliative or agonistic stimulus exhibited a higher probability of repeating the same behavior but a lower probability of performing the opposite behavior. These findings add to our understanding of the biological embedding at the molecular level. 


\section{Introduction:}

When animals are confronted with a conspecific, it is advantageous for them to be able to predict whether their interaction will likely be beneficial or harmful (Palmer and Kristan, 2011). While social stimuli can evoke a complex repertoire of behavioral responses appropriate to the situation, at least two primary valences of social interactions can be distinguished: positive affiliative or negative agonistic behavior. Positive affiliative behaviors favor both the actor and recipient (unless one of the individuals is infected with pathogens) and include behaviors such as parental care (Dulac et al., 2014), alloparental care (Stiver and Alonzo, 2011), and social grooming (Lehmann et al., 2007). Agonistic behaviors are intended to deter or harm the recipient and include behaviors such as threatening and aggression (Lorenz, 1966; Nelson and Trainor, 2007). The stimuli that evoke affiliative or agonistic behavior correlate with different physiological and internal states; agonistic behavior is related to stress and fear and the potential loss of valuable resources, while affiliative behavior is related to the positive effects of safety and social benefits (Anderson and Adolphs, 2014).

Social experience has a strong effect on an animal's future behavior (Oliveira et al., 2009). Biological embedding of social experience is a product of multiple processes including endocrine signaling, neuronal activity, and transcriptomic and epigenomic changes (Hertzman, 2012). For example, aggressive interactions in mice induce an increase in circulating testosterone levels and brain dopamine levels that lead to an increase in vigilance and aggression in future encounters (Maruska, 2015; Nelson and Trainor, 2007; Schwartzer et al., 2013). Mouse affiliative behaviors like parental care increase the secretion of estrogens and vasopressin, increasing the frequency of affiliative behavior in the future (Dulac et al., 2014; Li et al., 2015; Lim and Young, 2006).

Neurochemical changes occur relatively quickly and have a relatively immediate effect on the behavior and physiology of the animal. In contrast, changes in brain gene expression and chromatin structure typically take longer and are therefore less likely to have an immediate effect on behavior. Nevertheless, extensive brain transcriptomic changes have been observed in response to social challenges that evoke threatening or aggressive behavior, in both vertebrates and invertebrates (Bukhari et al., 2017; Rittschof et al., 2014; Saul et al., 2017; Shpigler et al., 2017b). Such neurogenomic changes are expected to affect future social interactions as a consequence of biological embedding of the social experience (Robinson, 2015). Consistent with this idea, bees subjected to a threatening signal showed increased aggression in subsequent lab and field assays (Alaux and Robinson, 2007; Shpigler et al., 2017b). These results raise the question of whether the experience of affiliative behavior also induces neurogenomic changes and then biases future behavior toward increased affiliation and decreased agonistic behavior.

Here we report on studies that examined this question by analyzing neurogenomic responses of adult worker honey bees (Apis mellifera) to a stimulus that triggers affiliative behavior. We used a laboratory assay we developed (Shpigler and Robinson, 2015) that gives individuals the opportunity to nurse a queen larva; because worker honey bees are essentially sterile, this type of 
alloparenting is strongly associated with evolutionary fitness. We measured gene expression in the mushroom bodies (MB), a higher order integration center in the insect brain that coordinates sensory input in multiple modalities with behavioral output (Vogt et al., 2014). Neurophysiological studies have demonstrated the involvement of the MB in learning and memory and decision making (Heisenberg, 2003; Martin et al., 1998; McGuire et al., 2001; McGuire et al., 2005). In addition, we have demonstrated a robust MB transcriptomic response to an agonistic social signal, i.e., a territorial intruder in a laboratory assay (Shpigler et al., 2017b). To probe the gene regulatory mechanisms underlying gene expression changes associated with an affiliative social opportunity, we also measured chromatin accessibility in the brain. Finally, we determined whether exposure to a queen rearing opportunity biases future behavior toward further performance of this affiliative behavior and against agonistic behavior.

A further goal of this study was to explore the question of whether neurogenomic responses to affiliative social stimulus and agonistic social stimulus differ in ways that suggest that valence detection has a molecular basis. Molecular mechanisms underlying valence detection have been demonstrated in other systems, as indicated by the following examples. The parasite Toxoplasma gondii was shown to reduce rat avoidance of predator odors by epigenetic modification in the amygdala (Dass and Vyas, 2014). In the fruit fly, aggression or courtship behavior is controlled by a known subset of neurons and can be modified via cell-specific splicing changes in the gene fruitless (Demir and Dickson, 2005; Koganezawa et al., 2016). Exposing mice to variety of rewarding or aversive experience induced unique expression response of immediate early genes in distinguish brain regions (Mukherjee et al., 2018). These examples suggest that valence detection has a molecular component that has not yet been examined at the transcriptomic level.

To facilitate an agonistic-affiliative comparative neurogenomic analysis, the present affiliative study was designed to parallel our published study on agonistic interaction (Shpigler et al., 2017b) as closely as possible. Although we have only studied one social behavior of each type, this comparison provides results that are consistent with the hypothesis that differences in brain transcriptomic are related to differences in the valence of social stimuli.

\section{Materials and methods: \\ Bees}

One-day-old bees were obtained from apiaries maintained by the University of Illinois Bee Research Facility, Urbana, IL, June-August 2014 and 2015. Frames of honeycomb containing pupae were removed from the colonies and placed in an incubator $\left(34^{\circ} \pm 1^{\circ} \mathrm{C}, 45 \% \pm 10 \% \mathrm{RH}\right)$. Newly emerged adult bees (1-18 h old) were placed in groups of 10; each bee within a group was marked with a unique color for individual recognition. Bees were kept in vertically oriented Petri dishes (100 X $20 \mathrm{~mm})$ with a beeswax foundation sheet placed on the base ("wall") of the dish to mimic in-hive conditions. Dishes were supplied with one tube of honey $(\sim 1.4 \mathrm{ml}), 30 \%$ sucrose solution $(2 \mathrm{ml})$ and pollen cake made of a mixture of pollen and $30 \%$ sugar solution $(\sim 10 \mathrm{~mm}$ 
diameter ball). For Experiment 1, three colonies were used, each headed by queens artificially inseminated with semen from a single drone (SDI). Because of haplodiploid, the resulting female worker offspring within each colony were highly related to each other (average coefficient of relatedness, $r=0.75$ ), thus decreasing within-colony genetic variation. For Experiment 2 , two of the same SDI colonies from Experiment 1 were used. For Experiment 3, two colonies headed by naturally mated queens (inseminated by multiple drones) were used. The bees from the different colonies in each experiment were not related to each other, making each colony an independent biological replicate of the experiment.

\section{Brood Care Assay}

We used a recently developed assay shown to induce natural queen rearing behavior in the laboratory (Shpigler and Robinson, 2015). Briefly, groups of ten 7-day-old bees housed in transparent plastic Petri dishes $(100 \times 20 \mathrm{~mm})$ were exposed to a 4-day-old queen larva located naturally in a waxen "queen cell" for $5 \mathrm{~min}$. The experiment was conducted in an incubator room set to mimic the normal in-hive conditions when brood care behavior is performed $\left(34^{\circ} \pm 0.5 \mathrm{C}\right.$, $50 \% \pm 10 \% \mathrm{RH})$. Detailed observations were performed for $5 \mathrm{~min}$ after the queen larva was introduced to the dish, during which the bees entered the queen cell to interact with the larva. We focused on two behaviors: cell inspection, which consists of short interactions $(<10 \mathrm{sec})$ and nursing, which consists of longer interactions (11-90 sec), feeding endogenously produced "royal jelly," and abdominal contractions. For each bee, we recorded the number of visits to the queen cell, the length of each visit, and the total amount of time spent in the cell out of the five-minute assay. A video of the behavioral assay can be found at: http://journals.plos.org/plosone/article?id=10.1371/journal.pone. 0143183

\section{Experiment 1: Effects of exposure to an affiliative stimulus on mushroom body gene expression}

Groups of ten bees were created as described above and assigned randomly to experimental or control treatments. For groups assigned to the experimental treatment, the brood care assay was performed as described above. For groups assigned to the control treatment, an empty queen cell from the same colony as the queen cell used for the experimental treatment was introduced. Although bees occasionally inspected the empty cell, its presence did not elicit any nursing behavior or alter their other behaviors in any discernable way. We believe this type of novel, but non-social stimulus should control for the effects of general arousal on MB gene expression. The queen cell and the control empty cell were introduced simultaneously (each to its respective group) and removed at the end of the 5-min assay. The bees were then left undisturbed for 30, 60 or $120 \mathrm{~min}$. The "nurse" bee that spent the longest amount of time in the queen cell in each dish (range: $45-169 \mathrm{sec}$, average: $83.9 \pm 4.5 \mathrm{sec} ; 80.9 \pm 4 \mathrm{sec} ; 64.3+2.5 \mathrm{sec}$ for colonies 1,2 and 3 respectively) was collected for transcriptomic analysis 30,60 or $120 \mathrm{~min}$ after the brood care assay. A normally behaving bee from the control dish was collected at the same time for comparison. The sampled bees were frozen immediately in liquid nitrogen and individually placed in $1.5 \mathrm{~mL}$ tubes stored in a $-80^{\circ} \mathrm{C}$ freezer for further analysis. For transcriptomic 
profiling, 10 pairs of experimental and matched control bees were used for each time point, summing to a total of 60 individuals per colony. The experiment was repeated with three different colonies, summing to a total sample size of 180 bees, each analyzed individually. Four bees (two paired experimental and control) were excluded from the analysis due to poor RNA quality, leaving a sample size of 176 individuals. The amount of time each bee spent in the queen cell was used to analyze the relationship between the intensity of the behavior and MB gene expression.

\section{Mushroom body dissection and RNA extraction}

MBs were isolated as in (Shpigler et al., 2017b). Briefly, bee heads were cut open and immersed in RNAlater-ICE (FisherThermo) at $-20^{\circ} \mathrm{C}$ for $14-18 \mathrm{~h}$. The heads were then dissected and the whole brain removed. The upper part of the midbrain containing mostly the mushroom bodies (MB) and the central brain was cut out and used for gene expression analysis. RNA extraction was performed with a PicoPure RNA Isolation Kit (Applied Biosystems; Lot \#: 1210063). 550 ng RNA from each sample (except for 19 samples that yielded 350-550 ng) were used for whole mRNA expression analysis. Sample RNA integrity was assessed using Bioanalyzer 2100 (Agilent).

RNA sequencing, data processing, and analysis

Library preparation and RNA-Seq was performed at the W. M. Keck Center for Comparative and Functional Genomics at the Roy J. Carver Biotechnology Center (University of Illinois) as described at (Shpigler et al., 2017b). Single-end RNA sequencing (using Illumina HiSeq2000) produced a median read depth of 22.98 million reads per sample (range: 9.20-35.68 million reads per sample). Sequencing reads were aligned to the $A$. mellifera 4.5 reference genome (Elsik et al. 2014) using TopHat 2 with Bowtie 2 . Most of the bees (176 out of 178) had $>80 \%$ of the transcriptome reads aligning to the A. mellifera genome. As social interaction can be also a platform for the transduction of pathogens and harm the recipience we also looked if the samples are contaminated with virus genes. All samples had $<0.5 \%$ of the reads aligning to the genome of the deformed wing virus (DWV), a major pathogen of the hone bee. These results suggest that the bees were relatively healthy. Numbers of reads per gene were counted with HTSeq-count, for 15,314 genes. A total of 10,653 genes had $>1$ count per million in $\geq 6$ samples; these genes were used for subsequent analyses. Gene expression levels at each time point were compared between the experimental and control groups using a general linear model (GLM), with colony as blocking factor, in edgeR (Robinson et al., 2010). P-value correction for multiple testing was done using the false discovery rates (FDR) method (Storey 2002); lists of differentially expressed genes (DEGs) were determined based on FDR $<0.05$. Fifty-four genes that are highly expressed in the hypopharnygeal glands (HPG) were excluded from the analysis since the HPG are close to the brain and can contaminate brain samples (Rittschof et al., 2014; supplementary table 9). Gene Ontology (GO) enrichment analysis (Ashburner et al., 2000) was performed on the DEG lists using a list of orthologous genes with Drosophila melanogaster (Huang et al., 2009). 
Comparison of mushroom body transcriptomic responses to an affiliative or agonistic stimulus We compared the gene expression results of our current study to our previously published study on the effect of exposure to an intruder bee on MB gene expression (Shpigler et al., 2017b). Data collection and analysis were performed identically in both studies. Overlaps between the DEG lists produced by the same analysis were compared using a hypergeometric test after setting the common universe of genes expressed in both studies (10,563 genes). The log fold-change of experiment vs. control of shared DEGs in each experiment was analyzed using a Pearson correlation test to evaluate the relationship of the gene expression response between the studies in the GLM and in the post-hoc time point analysis. Genes differentially expressed (FDR $<0.05)$ only in one study were categorized as either agonistic- or affiliative-responding genes. The uniquely responding genes were split into up- and down-regulated genes and GO enrichment analysis performed on each list.

\section{Transcriptional regulation of the $M B$ response to social stimuli}

To predict which transcription factors (TFs) regulate behavior- and time-dependent changes in gene expression related to affiliative (current study) and/or agonistic interactions (Shpigler et al., 2017b), a transcriptional regulatory network (TRN) was constructed base on gene expression data from both studies using the Analyzing Subsets of Transcriptional Regulators Influencing eXpression (ASTRIX) method (Chandrasekaran et al., 2011) as described in (Shpigler et al., 2017b). Briefly, ASTRIX uses gene expression data to identify strong regulatory interactions between TFs and their target genes. The predicted targets of TFs were defined as those genes that share very high mutual information $\left(p<10^{-6}\right)$ with a TF and have a high predictive ability (Correlation $\mathrm{R}>0.8$ ). The TRN was used to identify TFs whose predicted target genes were enriched in DEGs (behaving vs. control), as putative regulators of the MB transcriptomic response. Some TF and target gene sets were implicated in both affiliative and agonistic interactions and other were unique to only one.

Correlations between MB gene expression and behavioral intensity

Regression analysis of gene expression onto time spent in the queen cell was performed using a general linear model (GLM) in edgeR (Robinson et al., 2010). P-value correction for multiple testing was performed using the false discovery rates (FDR) method (Storey 2002), using a criterion of FDR $<0.05$. These analyses were based on 88 bees ( 30 in Colony 1 and 29 from Colonies 2 and 3) and a total of 10,527 genes had $>1$ count per million in e 9 samples; these genes were used for analysis of the relationship between behavioral intensity and gene expression.

Experiment 2: Effects of exposure to an affiliative stimulus on brain chromatin accessibility Histone H3 acetylated at lysine 27 (H3K27ac) is a marker of chromatin active sites, so sequencing the DNA near this marker provides good information about which genes have their chromatin accessible to TF binding (Creyghton et al. 2010; Rada-Iglesias et al. 2011). Experimental and control bees sampled from the brood care assay at two-time points, 30 and 120 
min, were collected from two SDI colonies (also used in Experiment 1). H3K27ac ChIP-seq was performed as described in (Shpigler et al., 2017b). Briefly, libraries of H3K27ac-ChIP marked DNA were prepared from pools of 10 brains from each experimental group and repeated for each colony for a total of 8 samples. In addition, two immunoprecipitations were performed as technical replicates with a single input control sample for a total of 24 libraries. The libraries were created and pooled to a final concentration of $10 \mathrm{nM}$ and sequenced on a single lane of an Illumina HiSeq 2500. Sequence data were mapped to the honey bee A. mellifera 4.5 reference genome. Mapped sequence data were analyzed using Hypergeometric Optimization of Motif EnRichment (HOMER) v4.7. Histone peaks were called from the Tag Directories with default settings, except that local filtering was disabled, and input filtering was set at two-fold over background to increase the sensitivity of the peak calling. Differential H3k27ac chromatin peaks were identified using the HOMER getDifferentialPeak.pl script, which looks for peaks $>2$-fold between experimental groups with a p-value of $10^{-4}$. For each peak we found the closest transcription start site (TSS) to identify the gene most likely to be affected by the change in accessibility. This list of genes was used for subsequent analysis.

\section{Experiment 3: Effects of exposure to affiliative and agonistic stimuli on future behavior}

Previous research (Shpigler et al., 2017b) showed that exposure to an intruder not only provokes an immediate attack but also leads to longer-term changes in behavior in response to a second intruder. We used the brood care assay to test for comparable effects of exposure to an affiliative stimulus. We also expanded the scope of our exploration of biological embedding by exposing bees to both an intruder and a queen larva to determine the specificity of the exposure on future behavior.

Each group of ten individually marked bees was exposed to a 4-day old queen larva in a queen cell (as described above) or an unrelated intruder bee (Shpigler et al., 2017b). Both social stimuli were presented for $5 \mathrm{~min}$ and the response of each bee was recorded. The group was left undisturbed for $2 \mathrm{~h}$ and then a second stimulus was given to the same group and the behavior recorded again. Stimuli were presented in the following pairings (first stimulus /second stimulus): intruder/intruder; queen larva/queen larva; intruder/queen larva (or queen larva/intruder). A bee that interacted with a queen larva for $>10 \mathrm{sec}$ was called a "nurse." The bee that responded most aggressively to the intruder (biting and/or stinging at least once) was called a "guard." Chi-square tests for independence were used to test if the distribution of bees responding as nurses or guards in the first and second assay was different than random; deviation from random would suggest a biasing of the second behavioral performance based the experience of the first. Sample sizes were as follows: intruder/intruder: 45 groups (435 bees); Queen larva/queen larva 26 groups (240 bees); and queen larva/intruder (or vice versa) 45 groups (442 bees). The bees were collected from two different colonies, each headed by naturally mated queens; each group contained bees from only a single colony. Behavioral observers were blind to the results of the first assay while conducting the second assay. 


\section{Statistical analysis}

Behavioral and transcriptomic analyses were performed in R. The TF network was built using the ASTRIX algorithm and analyzed in MATLAB. ChIP-seq data were analyzed using HOMER. Detailed descriptions of the methods used for statistical analysis for each experiment can be found in the individual subsections. RNA-seq and ChIP-seq raw and processed data are available at Gene Expression Omnibus (GEO) as a SuperSeries under accession number: GSE113132.

\section{Results}

Experiment 1: Effects of exposure to an affiliative stimulus on mushroom body gene expression

RNA-seq analysis of 176 bees from three unrelated colonies revealed that affiliative interactions with queen larvae had strong influences on MB gene expression. There were 501 differentially expressed genes ("DEGs," FDR $\leq 0.05,299$ upregulated and 202 downregulated) associated with exposure to a queen larva in a queen cell and the subsequent nursing behavior, compared to exposure to an empty queen cell. The upregulated genes were enriched for the GO terms "response to abiotic stimulus," "olfactory behavior" and "axonogenesis." The downregulated genes were enriched for the GO terms "neurological system process," "response to light stimulus" and "DNA metabolic process." There were 754 DEGs related to time after exposure to stimulus. These genes were weakly enriched ( 6 genes total) for the GO term "GPI anchor biosynthetic process". 332 DEGs were related to the interaction of nursing and time; these genes were enriched for the GO term "transcription factor activity" (GLM, FDR $<0.05$, Table S1 and S2).

The transcriptomic responses were\#dynamic and changed in character in the time immediately following the stimulus. In pair-wise comparisons there were 345, 712 and 410 DEGs detected at 30, 60 and 120 minutes, respectively, after an affiliative response to a queen larva, compared to control bees exposed to an empty queen cell. The overlap between the DEG lists for the threetime points was small - only 14 genes were differentially expressed across all three time points (Fig. 1A right, Table S3).

Comparison of mushroom body transcriptomic responses to an affiliative or agonistic stimulus The present affiliative behavior study was designed to parallel our previously published agonistic behavior study (Shpigler et al., 2017b). We compared the results of these two studies to explore the question of whether neurogenomic responses to affiliative and agonistic stimuli differ in ways that suggest that valence detection has a molecular basis (Fig S1).

To address questions regarding the role of valence in embedding of experience, we compared the DEG lists for the affiliative and agonistic responses at each of the three time points (Fig 1A). There were significant overlaps of DEGs across the two studies at all three time points (Fig 1B), with a significant positive correlation between genes upregulated in response to both stimuli at 
all three time points (Fig 1C). Only three genes were differentially expressed at all time points and in response to each stimulus: the immediate early gene $\mathrm{Hr} 38$, its paralog Hr38-like, and prohormone-2 (Fig 1D). The immediate early gene Egr-1 was also differentially expressed in both experiments, but only in the first hour. Most of the DEGs responded only to one of the stimuli but not to the other (Fig 1D).

In the GLM analyses there were 501 and 1039 DEGs related to exposure to either a queen larva or an intruder bee, respectively. The overlap between these DEG lists included 136 genes (hypergeometric test, $p=5.23 \mathrm{E}^{-30}$, Fig $2 \mathrm{~A}$ ). The expression of these genes was significantly positively correlated across the two studies $\left(\mathrm{R}^{2}=0.84 ; \mathrm{t}_{(135)}=26.6 ; p=2.54 \mathrm{E}^{-55}\right.$, Fig $\left.2 \mathrm{~B}\right)$. GO analysis revealed that the DEGs responding to both stimuli were enriched for two main molecular function GO terms, "transcription factor activity" (12 genes) and "unfolded protein binding" (8 genes).

We hypothesized that this shared set of DEGs captured the common component of the response to the two stimuli: the social nature of the signal. To explore this idea we compared the shared GLM gene list (136 genes), which captures the gene expression profile of bees responding to social stimuli, with another previously published DEG list of 605 genes related to responsiveness to the same two stimuli (Shpigler et al., 2017a). There was a significant overlap, but this only involved 18 genes across the two lists (hypergeometric test; $p=0.001$, Fig 2C). The 18 genes included several genes encoding molecular chaperones and the TF dimm.

We also explored this hypothesis by comparing our DEG lists associated with the response to either a queen larva or an intruder with a previously published mushroom body 546 DEG list; from an experiment in which bees were exposed to a nonsocial stimulus, a food reward given to bees in a feeder outside of the colony (McNeill et al., 2016). As McNeill et al. (2016) studied only a 60 -min time point, we used the data sets from the same time point from the present study. There was an overlap of eight genes responding to all three stimuli (hypergeometric test; $p=$ 0.001, Fig S2). These results showed that the MB transcriptomic response of 38 genes to the social stimuli had some elements in common with a non-social stimulus but was mostly distinct from it.

\section{Unique transcriptional response to agonistic and affiliative social interactions}

In addition to a core of genes responsive to both social stimuli in the MB, there also were hundreds of genes responding exclusively to either the affiliative or agonistic social stimulus overall and at each time point after stimulus presentation. In both cases the transcriptomic response was dynamic, and the temporal profiles were distinct. For affiliative behavior, the largest response was detected 60 minutes after the stimulus, while for the agonistic stimulus the largest response was detected after 120 minutes (Fig 1A). 
To better characterize the transcriptomic response to each social stimulus we split each time point-specific DEG list (Fig 1D) into up- and down-regulated genes, then conducted GO enrichment analysis to identify the highlighted functional categories in each case. At each time point, we identified different enrichments unique to each behavior (Table 1A and Table 1B, full list - Table S4). GO terms uniquely upregulated for the affiliative interaction included the biological processes "neuron differentiation" and "amine receptor activity," and the downregulated genes were enriched for "DNA replication." By contrast, for the agonistic interaction, uniquely upregulated processes included "chromosome organization" and "steroid hormone receptor activity." The down-regulated genes were enriched for "contractile fiber" and "oxidative phosphorylation."

We highlight one group of DEGs showing different expression patterns in the MB in response to the two different social stimuli, the amine receptors. Four receptors, octopamine receptor in $\mathrm{MB}$ $\left(O c m b\right.$, Fig 3A), Octopamine ${ }^{2}-1$ receptor $\left(O c t^{2} 1 R\right.$, Fig 3B), Octopamine ${ }^{2}-2$ receptor $\left(O c t^{2} 2 R\right.$, Fig 3C) and Dopamine 1 like receptor 2 (DopR12, Fig 3D) were all upregulated in response to the affiliative stimulus $60 \mathrm{~min}$ after the exposure, but only two were differentially expressed in response to the agonistic stimulus, $O c t^{2} 2 R$ at $60 \mathrm{~min}$ and $120 \mathrm{~min}$ (Fig 3C) and DopR12 at 30 $\min$ (Fig 3D).

\section{Transcriptional regulation of the $M B$ response to social stimuli}

A transcriptional regulatory network (TRN) was modeled from the RNA-seq data using ASTRIX (Chandrasekaran et al. 2011), using data from both the present study and from (Shpigler et al., 2017b). This analysis allowed us to identify transcription factors (TF) that are predicted to regulate gene expression in response to both social stimuli, and those predicted to regulate gene expression in response to one stimulus but not the other. The TRN included 8685 interactions between 242 TFs and 3352 target genes. The TRN was thus able to predict transcriptional relationships between a single TF and target genes for about $34 \%$ of the genes included in the analysis, a number similar to what was reported by Chandrasekaran et al. (2011). The proportion of the transcriptome predicted by ASTRIX is constrained by several factors such as the number of honeybee TFs that are unknown and the existence of non-linear interactions between regulators.

Similar to the DEG comparisons, the TRN analysis identified TFs that were differentially expressed in response to both stimuli and predicted to regulate DEGs that also were responsive to both stimuli. These shared TFs included the genes $\mathrm{Hr} 38$, Egr-1, CTCF, and usp.\#Also similar to the DEG comparisons, the TRN analysis identified TFs that were differentially expressed in response to either one or the other social stimulus and predicted to regulate DEGs that also responded to just one social stimulus. These unique affiliative TFs included the genes $c w o, b r k$, $f r u$ and $f t z-f l$. The unique TFs responding to the agonistic stimulus included the genes Deafl, Eip74EF, and SoxN. We also identified a group of TFs whose targets were enriched for DEGs responsive to both stimuli, but for different DEGs for each stimulus, suggesting that some TFs 
can orchestrate different molecular responses based on the nature of the stimulus (Fig 4, table S5).

Correlations between mushroom body gene expression and behavioral intensity

There was strong inter-individual variation in the amount of time spent nursing the queen larva in the brood care assay (range: $45-169$ seconds, $\mathrm{N}=88$ bees). A total of 88 genes showed a significant correlation between expression level in the MB and time spent nursing (GLM, FDR < 0.05 , Table S6), with 37 positively correlated and 51 negatively correlated. The positively correlated genes were enriched for the GO term "ion channel activity" and included three potassium channels CG5621; $\mathrm{I}_{\mathrm{h}}$-channel (Fig 5A) and $K C N Q$ - kcnq potassium channel. The negatively correlated genes were not enriched for any GO term and included the adenosine receptor gene $(A d o R)$, which is involved in the response to metabolic stress (Zemanova et al., 2016), Fig 5B). None of these genes were also DEGs in the comparisons reported above.

Experiment 2: Effects of exposure to an affiliative stimulus on brain chromatin accessibility Using an antibody against histone H3 acetylated at lysine 27 (H3K27ac), a mark of open chromatin and active regulatory elements, we identified chromatin differential accessibility peaks (DAPs, defined as a e 2-fold change in peak difference at $p<10^{-4}$ ) between nursing and control bees. In parallel to the RNA-seq work, we compared bees 30 and 120 min after exposure to a queen larva using pools of 10 whole brains from each of two colonies. We detected an average of $\sim 25,000$ chromatin peaks with an average $69 \pm 13.5$ DAPs between nursing and control bees. This is only $0.28 \%$ (range: $0.19 \%-0.63 \%$ ) of the peaks, which contrasts with the RNA-seq results at the same time points; the stimulus altered expression in hundreds of genes, representing $\sim 4 \%$ of the expressed genes.

There were 185 DAPs enriched in nursing bees for Colony 1 (152 and 33 at 30 and 120 min., respectively, with overlap of 3) and 151 for Colony 2 (60 and 91 at 30 and 120 min., respectively, 1 overlap gene), with a significant overlap between the colonies of 10 DAPs (hypergeometric test $p=1.7 \mathrm{E}-7$ ). This overlap is small but significant due to the large background. The DAPs from the nursing group from both colonies together were associated with genes enriched for the GO terms "synapse organization" and "phosphorylation." The enrichment results suggest that the changes in chromatin structure are related to the exposure to the affiliative stimulus. The TF Hormone receptor $4(\mathrm{Hr} 4)$ has a DAP in the nursing group in both colonies and is also upregulated at the RNA level at the $30 \mathrm{~min}$ time point. Some of the DAPs were located near a DEG (e.g., Hr4, hairy), but there was no significant overlap between the DEG and DAP lists.

There were 97 DAPs enriched in the control group for Colony 1 (52 and 45 at 30 and 120 min, respectively, with 1 overlap) and 119 for Colony 2 (46 and 73 at 30 and 120 min respectively, 1 overlap). There was a significant overlap of 7 DAPs across colonies (hypergeometric test, $p=$ 4.2E-7). The DAPs in the control group from both colonies were associated with genes enriched 
for the GO term "negative regulation of cell proliferation" and included a peak in the promoter of the gene encoding the TF vrille (vri) at $30 \mathrm{~min}$. vri is involved in locomotor rhythms and drives rhythmic transcription patterns normally peaking at dawn (Gunawardhana and Hardin, 2017). Vri also had a DAP in its promoter at $30 \mathrm{~min}$ but not at $120 \mathrm{~min}$ in the control group after exposure to an agonistic stimulus (Shpigler et al. 2017b). These data suggest that changes in vri regulation are involved in the MB response to both stimuli (Fig S3, Table S7 and S8).

\section{Experiment 3: Effects of exposure to affiliative and agonistic stimuli on future behavior}

The concept of biological embedding implies that past experience influences future behavior. We tested whether the performance of the bees upon exposure to brood care and intruder stimuli can predict the behavior of the bees to a second exposure two hours later. We exposed 24 groups of seven-day-old bees to a queen larva, left the bees undisturbed for two hours, then exposed them to a queen larva a second time. In the first trial, 60 bees (25\%) performed full nursing behavior, each one spending more than 30 seconds in the queen cell. In the second trial, a similar number of bees $(22 \%)$ performed this behavior, a proportion not significantly different from the first trial (Fisher's exact test, $p=0.450)$. However, 34 bees $(14 \%)$ performed nursing in both the first and second trials, a significantly higher proportion than expected by chance (Chi-square test for independence, $C_{(\mathrm{df}=1)}^{2}=58.5$, corrected $p=9.0 \mathrm{E}^{-14}$, Fig 6A). We exposed 46 groups to a parallel set of repeated intruder assays. In the first intruder trial, 121 bees $(28 \%)$ responded in a highly aggressive manner, biting and attempting to sting the intruder bee. In the second trial, 152 bees (36\%) responded aggressively, a significant increase in the number of aggressive bees (Fisher's exact test, $p=0.028$ ), indicating that interaction with an intruder increases the group response, consistent with the results reported in (Shpigler et al., 2017b), while interaction with a queen larva does not. Seventy bees (16\%) responded aggressively in both trials, much higher than expected by chance (Chi-square test for independence, $\mathrm{C}_{(\mathrm{df}=1)}^{2}=35.2$, corrected $p=8.7 \mathrm{E}^{-9}$, Fig $6 \mathrm{~B})$.

When we exposed 45 groups to both the intruder and brood care stimuli (with order randomized), 134 bees (30\%) performed nursing and $117(26 \%)$ aggression, but only 24 bees $(5.4 \%)$ responded to both stimuli, a lower proportion than expected by chance (Chi-square test for independence, $C_{(\mathrm{d}=1)}^{2}=7.23$, corrected $p=0.021$, Fig 6C). This is consistent with a strong division of labor in honey bee colonies, with nursing and guarding performed by distinct groups of bees (Robinson 1992).

\section{Discussion}

Affiliative social interactions exert strong influences on gene expression in the mushroom bodies of the honey bee brain, even after a short exposure, initiating sustained and dynamic transcriptomic responses. There were hundreds of genes differentially expressed at each time point with few genes overlapping, as well as different molecular pathways more centrally 
involved at each time point. These results demonstrate that the MB are very responsive to stimuli associated with brood care behavior, an affiliative social interaction.

The transcriptomic changes in the MB induced by exposure to a queen larva persist long after the performance of brood care behavior, raising the question of the function of the changes. Queen larvae require extensive care for a period of five days (Laidlaw and Page, 1997), thus the 4-dayold larvae used in this experiment required care for one additional day. We suggest that an encounter with a larva is reliable cue priming bees for future nursing behavior. Further we propose that the observed transcriptomic differences reflect a change in neurogenomic state that increases the likelihood of performing this behavior and orchestrates changes in physiology required for its sustained performance. This hypothesis is consistent with the results of the behavioral analyses, which showed that performing brood care over a five-minute period resulted in an increased likelihood of exhibiting the same behavior in the future.

The large number of differentially expressed genes responding in the MB to queen larva exposure suggests that many biological systems are involved in orchestrating brood care behavior. For example, the upregulated genes were enriched for the GO term "olfactory behavior," while the downregulated were enriched for "visual perception." These results agree with honey bee ecology; nursing is conducted in the darkness of the hive, mediated by olfactory signals (Le Conte et al., 1994).

Another example is related to the circadian rhythm system. Honey bee larvae are fed around the clock; we would expect to find changes in the circadian rhythm system (Bloch et al., 2001, Toma et al., 2000), and we did. The genes vri, cwo, and TIM2, which are part of the core circadian clock system, showed changes in expression in response to the affiliative stimulus. Vri also displayed altered chromatin accessibility and expression level after agonistic interaction. The central role of this TF regulating circadian transcription associated with the onset of activity (Gunawardhana and Hardin, 2017) suggests that chromatin modifications leading to differential expression may play an important role in the response of nurse bees to the opportunity to rear a queen.

However, changes in brain DNA accessibility over the time course that we tested were limited and included only a small fraction of open chromatin regions throughout the genome. Nevertheless, this small number of DAPs was associated with genes enriched for the GO term synapse organization, suggesting that changes in chromatin accessibility after the exposure to an affiliative stimulus were not random. The list of genes closest to the DAPs overall did not overlap significantly with DEGs, and we thus cannot establish a general relationship between the changes in chromatin accessibility and gene expression. This is similar to what was reported for the effects of agonistic interaction on brain DNA accessibility (Shpigler et al., 2017b) and to previous studies of agonistic response in mice (Saul et al., 2017). We therefore suggest that the 
transcriptomic changes detected in response to social stimuli may be the result of transcriptional regulatory tuning on already accessible chromatin.

Differences in DNA methylation also are known to be related to different behavioral states in honey bees (Herb et al., 2012), and changes in 50 methylation sites were detected two hours after individuals were exposed to an intruder (Herb et al., 2018). We thus suggest that epigenetic changes may also be part of the response to the affiliative stimulus, but they act predominantly on a longer time scale than what we tested here, setting the stage for later action. However, we do not rule out the possibility that a more sensitive method for detecting epigenetic modifications at the level of individual brains or brain regions may be able to provide new insights.

The discovery of genes expressed in the MB that respond in the same direction to both an affiliative (this study) and agonistic (Shpigler et al., 2017b) stimulus provides further evidence that this brain region is involved in processing social information (Shpigler et al., 2017a). The similarity of the transcriptional responses is significant for two reasons. First, the two social stimuli are very different and lead to different behavioral outcomes. Second, the bees were from three independent colonies in each experiment (one colony was used in both experiments) and they were collected two years apart. These factors have been shown to have a strong influence on brain gene expression in honey bees (Naeger and Robinson, 2016). Hence, the similarity between these two experiments increases our confidence in the experimental design and in the robustness of the similarities.

We identified a total of 140 genes with similar responses to both social stimuli in comparison to a response to an inanimate control stimulus. Because the control group helps account for neurogenomic changes associated with general arousal (Cullinan et al. 1995), these responses appear to be specific to social stimuli. Supporting this inference, only a few of these genes were also differentially expressed in a study that measured the honey bee MB transcriptomic response to a food reward (McNeill et al. 2016). Among these 140 shared genes, we identified TFs that might drive the core social transcriptomic responses in both behavioral contexts. The response was dynamic with little overlap in gene expression between the time points. This finding suggests that by sampling over a time course instead of at a single point, we were able to outline the temporal dynamics of parts of the molecular response to social stimuli. The shared genes were enriched for nuclear receptors like $\mathrm{Hr} 38$ (homolog of mammalian $\mathrm{Nr} 4 \mathrm{a}$ ) and chaperones, which have a role in nuclear receptor signal transduction (Kurakula et al., 2014; Sever and Glass, 2013). The shared genes also overlapped with genes related to social responsiveness in humans (Shpigler et al., 2017a), suggesting that at least some, but not all, of these genes are involved in social signal transduction, the common character of both stimuli.

There are different ways that the common genes responding to both stimuli might be involved in the encoding of stimulus valence. One possibility is that this occurs based on differential anatomical localization of neuronal circuits in the MB. Alternatively, the genes may be 
expressed in a specific "social nucleus" within the MB while valence type is encoded by other genes. Because the honey bee MB contains approximately 450,000 neurons constituting about half of the honey bee brain cells - and our data are drawn from a heterogeneous mix of those cells (Fahrbach, 2006) - the present data set cannot be used to distinguish between these two hypotheses. Examples for both mechanisms exist: in fruit flies, the behaviors of approaching or avoiding an odor stimulus are affected by different output neurons located in the MB (Aso et al., 2014; Cervantes-Sandoval and Davis, 2012). By contrast, valence in the context of mating and aggression, in both fruit flies and mice, is encoded by overlapping neural networks (Anderson, 2016). Deciding between these two hypotheses will requires mRNA localization in the brains of responding bees by in situ hybridization (Kiya and Kubo, 2011; Lutz and Robinson, 2013; McNeill and Robinson, 2015).

While there were common responses of genes in the MB to both affiliative and agonistic stimuli, most of the expression responses were specific to either stimulus. These results suggest that distinct molecular pathways encode the valence of the stimulus in the brain. This conclusion is tempered by the fact that we only tested one stimulus in each valence category.

The behavioral results reported here suggest that stimulus-specific transcriptomic responses shift the brain to different neurogenomic states, characterized by differential responses to affiliative and agonistic stimuli. This is consistent with studies of male cichlid fish, which respond to new reproductive opportunities with morphological, physiological, neurobiological and behavioral changes that result in shifts from subordinate to dominant status (Fernald, 2015). We propose that large-scale changes in gene expression in response to social stimuli are part of the biological embedding process of social experiences, which prepares individuals for future encounters. We observed bees exposed to the affiliative stimulus were more likely to respond to affiliative stimulus and less likely to respond to the agonistic stimulus, and vice versa. The evidence for this effect is strongest at the 120 min time point, where both transcriptomic and behavioral data show changes. The stimulus-specific transcriptomic responses observed here may be related to positive feedback mechanisms hypothesized to increase specialization and build division of labor between workers, as suggested by the response threshold hypothesis for division of labor (Theraulaz et al., 1998).

One interesting aspect of the stimulus-specific transcriptomic responses relates to the different expression patterns of the genes encoding biogenic amine receptors. Octopaminergic cells were found to be related to appetitive learning and not to aversive learning in flies and crickets (Iliadi et al., 2017; Mizunami and Matsumoto, 2017). Dopaminergic cells are involved in aversive learning and aggression in fly (Alekseyenko et al., 2013). Also, dopamine enhances aggression among honey bee virgin queens (Farkhary, 2017). These parallels between aversive vs appetitive learning and agonistic vs. affiliative social interactions suggest that the same neurotransmitters encode the valence of the signal in both contexts. We suggest this could be a particularly fruitful line of study. 
Finally, we found a set of genes whose expression is correlated with the intensity of nursing behavior. Behavioral intensity can be controlled by neuronal activity, which depends in part on the number of membrane ion channels (Libster et al., 2015; Veys et al., 2013), but the relationship between variation in behavioral intensity and variation in brain gene expression is less well understood. Consistent with these findings, the intensity-correlated genes we found were enriched for GO term "ion channel activity" including three potassium channels, suggesting that individual differences in the intensity of the behavioral response are related in some way to variation in potassium channel- related neuronal activity. These genes were not differentially expressed between nurse and control bees, suggesting that the signal itself and the intensity of the behavioral response are encoded differently at the molecular level. Similar correlations between brain gene expression and aggressive intensity have been reported for stickleback fish (Sanogo et al., 2012). These results suggest that interindividual differences in behavior are rooted in transcriptomic differences, that themselves may be related to both heredity and environmental influences.

Our study demonstrates how short affiliative social interactions powerfully affect the brain transcriptomic profile of honey bees, implicating a variety of biological processes including the biogenic amine neuromodulators and changes in ion channels and epigenetic regulation. The transcriptomic modifications are unique to the type of the interaction and prime the bees for future situations based on the reliable signals gathered through experience. The findings suggest that transcriptomic changes are part of the process of biological embedding of social signals that prepare individuals to behave adaptively in the future. How these transcriptomic changes specifically affect neuronal tuning to social stimuli to modify future behavior needs to be addressed in future studies. 


\section{Figure Legends}

Figure 1: Comparison of genes in the MB responsive to an affiliative stimulus in this study and an agonistic stimulus in a previous study. (A) Venn diagram of differentially expressed genes (DEGs, FDR < 0.05) at 30,60 and 120 minutes in response to a short agonistic interaction (left, yellow), or affiliative interaction (right, blue). The numbers inside the circles are numbers of DEGs. (B) Venn diagram of lists of differentially regulated genes in agonistic (yellow), affiliative (blue) and in both (green) interactions; at $30 \mathrm{~min}$ (left), $60 \mathrm{~min}$ (middle) and $120 \mathrm{~min}$ (right). $* * *$ significant overlap (hypergeometric test with Bonferroni correction $\mathrm{p}<0.0001$ ) between the gene lists (universe - 10504 genes). (C) Correlation of the log fold change (experimental vs control) in expression of the shared responding genes at $30 \mathrm{~min}$ (left), $60 \mathrm{~min}$ (middle) and $120 \mathrm{~min}$ (right). Each green diamond is a single gene; the line depicts the linear regression model for the relationship of gene expression in both conditions. $R^{2}$ and $p$-value were obtained from Pearson correlation analysis. (D) Venn diagram of differentially expressed genes (DEGs, FDR < 0.05) at 30,60 and 120 minutes, uniquely responsive to agonistic interaction (left, yellow), responsive in both conditions (middle, green), and uniquely responsive in affiliative interaction (right, blue). The numbers inside the circles are numbers of DEGs. Previously published results in (Shpigler et al., 2017b). See Fig S1 for more detailed information related to these results.

Figure 2: Comparison of genes in the $M B$ responsive to affiliative and agonistic stimuli in this study and a previous study. (A) Venn diagram of DEGs related to behavioral response using the GLM analysis of agonistic and affiliative interaction. *** significant overlap (hypergeometric test with Bonferroni correction $p<0.0001$ ) between the gene lists (universe 10,504 genes). (B) Correlation of the log fold change (experiment vs. control) in expression of the shared responding genes. Each green diamond is a single gene; the line depicts the liner regression model for the relationship of gene expression in both conditions. $\mathrm{R}^{2}$ and $\mathrm{p}$-value were obtained from Pearson correlation analysis. (C) Venn diagram of the shared responding genes and gene list related to social responsiveness in honey bee (Shpigler et al., 2017a). *** significant overlap (hypergeometric test $\mathrm{p}<0.0001$ ) between the gene lists (universe -10504 genes).

Figure 3: Effect of exposure to affiliative and agonistic stimuli on the expression of genes encoding biogenic amine receptors in the MB. Expression level (cpm) of 4 biogenic amine receptor genes. Octopamine receptor in the Mushroom body (A); Octopamine ${ }^{2} 1$ receptor (B); C. Octopamine ${ }^{2} 2$ receptor (C); Dopamine-1 receptor-2 (D). Red: gene expression response in agonistic interaction (intruder assay); Blue: gene expression response to affiliative interaction (brood care assay); Black: control gene expression after exposure to an inanimate object. * significant differences in expression between experimental and control (FDR corrected p-value $<$ $0.05)$. 
Figure 4: Transcription factors predicted to regulate the transcriptomic response to affiliative and agonistic stimuli in the MB, based on transcriptional regulatory network reconstruction. The network includes $242 \mathrm{TFs}$, each one shown as a node marked by a circle. The TFs are color-coded; Dark green: TFs enriched for the DEGs in the target gene set with significant overlap in both conditions; Light green: TFs enriched for DEGs in the target gene set in both conditions but not the same DEGs; Red: TFs enriched for DEGs in the target gene set only at the agonistic interactions; Blue: TFs enriched for DEGs in the target gene set only in the affiliative interaction; Grey: TFs without enrichment for DEGs in their target gene set. (Full list of TF and targets can be found at Table S7).

Figure 5: Correlation between nursing intensity and MB gene expression. Expression level (cpm) of genes encoding $\mathrm{I}_{\mathrm{h}}$-channels (A) and adenosine receptors (B) as a function of the amount of time (seconds) a bee spent visiting the queen cell during a 5-minute assay. Each square represents a single bee; the colors, red, green and blue represent Colonies 1, 2 and 3, respectively. $\mathrm{R}^{2}$ is the result of Pearson correlation test, $\mathrm{p}-$ FDR corrected $\mathrm{p}$-value.

Figure 6: The relationship between past and future behavior. The probability that a bee will respond to a queen larva (A) or intruder (B) was significantly higher if she previously responded to the same stimulus, but significantly lower $(\mathbf{C})$ if she responded to the other stimulus. Number of bees responding in each assay are inside the circles, $\mathrm{N}$ is the number of groups tested, $\mathrm{p}$-value is the result of a chi-square test for independence followed by Bonferroni correction. The arrow represents the direction of the significant, (up - higher than chance, down - lower than chance).

\section{Table 1 Legend}

Table 1: GO enrichment analysis of differentially expressed genes in the MB responsive uniquely to affiliative (A) or agonistic (B) stimuli. Each list of DEGs at each time point was separated into up- and downregulated genes in comparison to the control group. The enrichment analysis was done using orthologous genes from Drosophila melanogaster using GO-FAT analysis in DAVID. The tables include representative GO terms from each time point / behavior. Count: number of genes in the list; Enrichment fold: relative number of GO-related genes in the DEG list in comparison to the number of the GO-related gene in the total list; $p$-value from Fisher's exact test, Benjamini - FDR correction for the p-value. 


\section{References}

Alaux, C. \& Robinson G.E. (2007) Alarm pheromone induces immediate-early gene expression and slow behavioral response in honey bees. J Chem Ecol, 33, 1346-1350.

Alekseyenko, O.V., Chan, Y.B., Li, R. \& Kravitz, E.A. (2013) Single dopaminergic neurons that modulate aggression in Drosophila. Proc Natl Acad Sci U S A 110, 6151-6156.

Anderson, D.J. (2016) Circuit modules linking internal states and social behaviour in flies and mice. Nat Rev Neurosci 17, 692-704.

Anderson, D.J. \& Adolphs, R. (2014) A Framework for Studying Emotions across Species. Cell 157,187-200.

Ashburner, M., Ball, C.A., Blake, J.A., Botstein, D., Butler, H., Cherry, J.M., Davis, A.P., Dolinski, K., Dwight, S.S., Eppig, J.T., Harris, M.A., Hill, D.P., Issel-Tarver, L., Kasarskis, A., Lewis, S., Matese, J.C., Richardson, J.E., Ringwald, M., Rubin, G.M. \& Sherlock, G. (2000) Gene Ontology: tool for the unification of biology. Nat Genet 25, $25-$ 29.

Aso, Y., Sitaraman, D., Ichinose, T., Kaun, K.R., Vogt, K., Belliart-Guérin, G., Plaçais, P.Y., Robie, A.A., Yamagata, N., Schnaitmann, C., Rowell, W.J., Johnston, R.M., Ngo, T.B., Chen, N., Korff, W., Nitabach, M.N., Heberlein, U., Preat, T., Branson, K.M., Tanimoto, H., Rubin, G.M. \& Luo, L. (2014) Mushroom body output neurons encode valence and guide memory-based action selection in Drosophila. eLife. 3, e04580.

Bloch, G., Toma, D.P. \& Robinson, G.E. (2001) Behavioral rhythmicity, age, division of labor and period expression in the honey bee brain. J Biol Rhythms 16, 444-456.

Bukhari, S.A., Saul, M.C., Seward, C.H., Zhang, H.M., Bensky, M., James, N., Zhao, S.D., Chandrasekaran, S., Stubbs, L. \& Bell, A.M. (2017) Temporal dynamics of neurogenomic plasticity in response to social interactions in male threespined sticklebacks. PLoS Genet 13, e1006840.

Cervantes-Sandoval, I. \& Davis, R.L. (2012) Distinct traces for appetitive versus aversive olfactory memories in DPM neurons of Drosophila. Curr Biol 22, 1247-52.

Chandrasekaran, S., Ament, S.A., Eddy, J.A., Rodriguez-Zas, S.L., Schatz, B.R., Price, N.D. \& Robinson, G.E. (2011) Behavior-specific changes in transcriptional modules lead to distinct and predictable neurogenomic states. Proc Natl Acad Sci U S A 108, 1802018025.

Creyghton, M.P., Cheng, A.W., Welstead, G.G., Kooistra, T., Carey, B.W., Steine, E.J., Hanna, J., Lodato, M.A., Frampton, G.M., Sharp, P.A., Boyer, L.A., Young, R.A. \& Jaenisch, R. (2010) Histone H3K27ac separates active from poised enhancers and predicts developmental state. Proc Natl Acad Sci U S A 107, 21931-21936.

Cullinan, W.E., Herman, J.P., Battaglia, D.F., Akil, H. \& Watson, S.J. (1995) Pattern and timecourse of immediate-early gene-expression in rat-brain following acute stress. Neuroscience 64:477-505

Dass, S.A.H. \& Vyas, A. (2014) Toxoplasma gondii infection reduces predator aversion in rats through epigenetic modulation in the host medial amygdala. Mol Ecol 23, 6114-6122. 
Demir, E. \& Dickson, B.J. (2005) fruitless splicing specifies male courtship behavior in Drosophila. Cell 121:785-794

Dulac, C., O'Connell, L.A \& Wu, Z. (2014) Neural control of maternal and paternal behaviors. Science 345:765-770

Fahrbach, S.E. (2006) Structure of the mushroom bodies of the insect brain. Annu Rev Entomol 51, 209-232.

Farkhary S.I., Ken, Hayashi., Shinya, H., Harano, K., Koyama, S. \& Satoh, T. (2017) Fighting and Stinging Responses are Affected by a Dopamine Receptor Blocker Flupenthixol in Honey Bee Virgin Queens J Insect Behav 30, 717-727.

Fernald, R.D. (2015) Social behaviour: Can it change the brain? Anim Behav 103, 259-265.

Gunawardhana, K.L., Hardin, P.E. (2017) VRILLE Controls PDF Neuropeptide Accumulation and Arborization Rhythms in Small Ventrolateral Neurons to Drive Rhythmic Behavior in Drosophila. Curr Biol 27, 3442-3453.

Heisenberg, M. (2003) Mushroom body memoir: From maps to models. Nat Rev Neurosci 4,266-275.

Herb, B.R., Shook, M.S., Fields, C.J. \& Robinson, G.E. (2018) Defense against territorial intrusion is associated with DNA methylation changes in the honey bee brain. BMC Genomics 19, 216.

Herb, B.R., Wolschin, F., Hansen, K.D., Aryee, M.J., Langmead, B., Irizarry, R., Amdam, G.V. \& Feinberg, A.P. (2012) Reversible switching between epigenetic states in honeybee behavioral subcastes. Nat Neurosci 15, 1371-1373.

Hertzman, C. (2012) Putting the concept of biological embedding in historical perspective. Proc Natl Acad Sci U S A 109, 17160-17167.

Huang, D.W., Sherman, B.T. \& Lempicki, R.A. (2009) Systematic and integrative analysis of large gene lists using DAVID bioinformatics resources. Nat Protoco 4, 44-57.

Iliadi, K.G., Iliadi, N. \& Boulianne, G.L. (2017) Drosophila mutants lacking octopamine exhibit impairment in aversive olfactory associative learning. Eur J Neurosci 46, 2080-2087.

Kiya, T. \& Kubo, T. (2011) Dance Type and Flight Parameters Are Associated with Different Mushroom Body Neural Activities in Worker Honeybee Brains. PLoS One 6, e19301.

Koganezawa, M., Kimura, K. \& Yamamoto, D. (2016) The Neural Circuitry that Functions as a Switch for Courtship versus Aggression in Drosophila Males. Curr Biol 26, 1395-1403.

Kurakula, K., Koenis, D.S., van Tiel, C.M. \& de Vries, C.J. (2014) NR4A nuclear receptors are orphans but not lonesome. Biochim Biophys Acta 1843, 2543-2555.

Laidlaw H.H. \& Page, R.E. (1997) Queen rearing and bee breeding. Wicwas Press, Cheshire CT USA.

Le Conte, Y., Sreng, L \&, Trouiller, J. (1994) The recognition of larvae by worker honeybees. Naturwissenschaften 81, 462-465.

Lehmann, J., Korstjens, A.H. \& Dunbar, R.I.M. (2007) Group size, grooming and social cohesion in primates. Anim Behav 74, 1617-1629. 
Li, Y.N., Lian, Z.M., Wang, B., Tai, F.D., Wu, R.Y., Hao. P. \& Qiao XF (2015) Natural variation in paternal behavior is associated with central estrogen receptor alpha and oxytocin levels. J Comp Physiol A 201, 285-293.

Libster, A.M., Title, B. \& Yarom, Y. (2015) Corticotropin-releasing factor increases Purkinje neuron excitability by modulating sodium, potassium, and I-h currents. J Neurophysiol 114, 3339-3350.

Lim, M,M. \& Young, L.J. (2006) Neuropeptidergic regulation of affiliative behavior and social bonding in animals. Horm Behav 50, 506-517.

Lorenz, K. (1966) On aggression. Harcourt, New York.

Lutz, C.C. \& Robinson, G.E. (2013) Activity-dependent gene expression in honey bee mushroom bodies in response to orientation flight. J Exp Biol 216, 2031-2038.

Martin, J.R., Ernst, R. \& Heisenberg, M. (1998) Mushroom Bodies Suppress Locomotor Activity in Drosophila melanogaster. Learn Mem 5, 179-191.

Maruska, K.P. (2015) Social Transitions Cause Rapid Behavioral and Neuroendocrine Changes. Integr Compar Biol 55, 294-306

McGuire, S.E., Deshazer, M. \& Davis, R.L. (2005) Thirty years of olfactory learning and memory research in Drosophila melanogaster. Prog Neurobiol 76, 328-347.

McGuire, S.E., Le, P.T. \& Davis, R.L. (2001) The role of Drosophila mushroom body signaling in olfactory memory. Science 293, 1330-1333.

McNeill, M.S., Kapheim, K.M., Brockmann, A., McGill, T.A.W. \& Robinson, G.E. (2016) Brain regions and molecular pathways responding to food reward type and value in honey bees. Genes Brain Behav 15, 305-317.

McNeill, M.S., Robinson, G.E. (2015) Voxel-based analysis of the immediate early gene, c-jun, in the honey bee brain after a sucrose stimulus. Insect mol biol 24, 377-90.

Mizunami, M. \& Matsumoto, Y. (2017) Roles of Octopamine and Dopamine Neurons for Mediating Appetitive and Aversive Signals in Pavlovian Conditioning in Crickets. Front Physiol 8, 1027.

Mukherjee, D., Ignatowska-Jankowska, B.M., Itskovits, E., Gonzales, B., Turm, H., Izakson, L., Haritan, D., Bleistein, N., Cohen, C., Amit, I., Shay, T., Grueter, B., Zaslaver, A. \& Citri, A. (2018) Salient experiences are represented by unique transcriptional signatures in the mouse brain. eLife 7, e31220.

Naeger, N.L. \& Robinson, G.E. (2016) Transcriptomic analysis of instinctive and learned reward-related behaviors in honey bees. J Exp Biol 219, 3554-3561.

Nelson, R.J. \& Trainor, B.C. (2007) Neural mechanisms of aggression. Nat Rev Neurosci 8, 536546.

Oliveira, R.F., Silva, A. \& Canario, A.V.M. (2009) Why do winners keep winning? Androgen mediation of winner but not loser effects in cichlid fish. P Roy Soc B-Biol Sci 276, 22492256.

Palmer, C.R. \& Kristan, W.B. (2011) Contextual modulation of behavioral choice. Curr Opin Neurobiol 21, 520-526. 
Rada-Iglesias A, Bajpai R, Swigut T, Brugmann SA, Flynn RA, Wysocka J (2011) A unique chromatin signature uncovers early developmental enhancers in humans. Nature 470, 279-283.

Rittschof, C.C., Bukhari, S.A., Sloofman, L.G., Troy, J.M., Caetano-Anolles, D., Cash-Ahmed, A., Kent, M., Lu, X., Sanogo, Y.O., Weisner, P.A., Zhang, H., Bell, A.M., Ma, J., Sinha, S., Robinson, G.E. \& Stubbs, L. (2014) Neuromolecular responses to social challenge: Common mechanisms across mouse, stickleback fish, and honey bee. Proc Natl Acad Sci U S A 111, 17929-17934.

Robinson, G.E. (2015) Brains work via their genes just as much as their neurons. In: The conversation. https://theconversation.com/brains-work-via-their-genes-just-as-much-astheir-neurons-47522.

Robinson, M.D., McCarthy, D.J., Smyth, G.K. (2010) edgeR: a Bioconductor package for differential expression analysis of digital gene expression data. Bioinformatics 26, 139140.

Sanogo, Y.O., Band, M., Blatti, C., Sinha, S. \& Bell, A.M. (2012) Transcriptional regulation of brain gene expression in response to a territorial intrusion. P Roy Soc B-Biol Sci 279, 4929-4938.

Saul, M.C., Seward, C.H., Troy, J.M., Zhang, H.M., Sloofman, L.G., Lu, X.C., Weisner, P.A., Caetano-Anolles, D., Sun, H., Zhao, S.D., Chandrasekaran, S., Sinha, S. \& Stubbs, L. (2017) Transcriptional regulatory dynamics drive coordinated metabolic and neural response to social challenge in mice. Genome Res 27, 959-972.

Schwartzer, J.J., Ricci, L.A. \& Melloni, R.H. (2013) Prior Fighting Experience Increases Aggression in Syrian Hamsters: Implications for a Role of Dopamine in the Winner Effect. Aggressive Behav 39, 290-300.

Sever, R. \& Glass, C.K. (2013) Signaling by Nuclear Receptors. CSH Perspect Biol. 5, a016709.

Shpigler, H.Y. \& Robinson, G.E. (2015) Laboratory Assay of Brood Care for Quantitative Analyses of Individual Differences in Honey Bee (Apis mellifera) Affiliative Behavior. PLoS One 10, e0143183.

Shpigler, H.Y., Saul, M.C., Corona, F., Block, L., Ahmed, A.C., Zhao, S.D. \& Robinson, G.E. (2017a) Deep evolutionary conservation of autism-related genes. Proc Natl Acad Sci U S A 114, 9653-9658.

Shpigler, H.Y., Saul, M.C., Murdoch, E.E., Cash-Ahmed, A.C., Seward, C.H., Sloofman, L., Chandrasekaran, S., Sinha, S., Stubbs, L.J. \& Robinson, G.E. (2017b) Behavioral, transcriptomic and epigenetic responses to social challenge in honey bees. Genes Brain Behav 16, 579-591.

Stiver, K..A \& Alonzo, S.H. (2011) Alloparental care increases mating success. Behav Ecol 22, 206-211.

Theraulaz, G., Bonabeau, E. \& Deneubourg, J.L. (1998) Response threshold reinforcements and division of labour in insect societies. Proc Biol Sci 265, 327-332. 
Toma, D.P., Bloch, G., Moore, D. \& Robinson, G.E. (2000) Changes in period mRNA levels in the brain and division of labor in honey bee colonies. Proc Natl Acad Sci U S A 97, 6914-6919.

Veys, K., Snyders, D. \& De Schutter, E. (2013) Kv3.3b expression defines the shape of the complex spike in the Purkinje cell. Front Cell Neurosci 7, 205.

Vogt, K., Schnaitmann, C., Dylla, K.V., Knapek, S., Aso, Y., Rubin, G.M. \& Tanimoto, H. (2014) Shared mushroom body circuits underlie visual and olfactory memories in Drosophila. eLife 3, e02395.

Zemanova, M., Staskova, T. \& Kodrik, D. (2016) Role of adipokinetic hormone and adenosine in the anti-stress response in Drosophila melanogaster. J Insect Physiol 91-92, 39-47. 


\section{Acknowledgments}

We thank D.C. Nye for managing the honey bee colonies; A. Hernandez (W.M. Keck Center for Comparative and Functional Genomics at the Roy J. Carver Biotechnology Center) for expert oversight in generating the DNA and RNA sequences; C.C. Lutz for editorial assistance; and members of the Robinson laboratory for comments that improved the manuscript. This research was supported by grant SFLife 291812 from the Simons Foundation (LJS and GER, PIs) and Vaadia-BARD Postdoctoral Fellowship Award No. FI-462-2012 to HYS. The authors declare no conflict of interests.

\section{Supporting information:}

Figure S1: Comparison of genes in the MB responsive to an affiliative stimulus in this study and an agonistic stimulus in a previous study. Each heat map includes all DEGs (based on a comparison of social and control stimuli) from both studies at three time points, $30 \mathrm{~min}$ (left), 60 min (middle) and $120 \mathrm{~min}$ (right). Each column represents a colony / experimental group, high expression levels are coded with cold colors (blues) and low expression with hot colors (yellows and reds). The colored column to the left of the heat map marks the genes as DEGs in response to an affiliative stimulus (blue), agonistic stimulus (red) or both (green).

Figure S2: Comparison of genes in the MB responsive to affiliative and agonistic stimuli in this study and a non-social stimulus in a previous study. Venn diagram of differentially expressed genes (DEGs, FDR < 0.05) 60 min after the response to a short agonistic interaction (yellow), affiliative interaction (blue) or non-social (food reward) stimulus. Genes responding only to social stimuli are marked in green. Previously published results from (McNeill et al., 2016).

Figure S3: Differentially accessible chromatin peaks in proximate region to the transcription factor Vrille. Top: Gene model from the A. mellifera 3.2 official gene set (OGS), Middle: H3k27ac peaks for experimental (red) and control (blue) bees from Colony 1, $30 \mathrm{~min}$ (top) and $120 \mathrm{~min}$ (bottom) after exposure to a queen larva. The differentially accessible peak is marked in a gray box.

Table S1. Affiliative behavior mushroom body RNAseq GLM results.

Table S2. Affiliative behavior mushroom body RNAseq time point results.

Table S3. Affiliative behavior mushroom body RNAseq DEGs, GO enrichment analysis.

Table S4. Unique and shared DEGs for affiliative and agonistic social interaction GO enrichment analysis

Table S5. Affiliative and agonistic behavior mushroom body transcriptional regulatory network (TRN) analysis.

Table S6. Correlation between MB gene expression and nursing behavior intensity.

Table S7. Affiliative behavior whole brain sequencing of histone H3-acetylated at lysine 27

(H3K27ac) ChIPseq-related DNA results. 
Table S8. Affiliative behavior whole brain H3K27ac ChIPseq GO analysis.

Full agonistic behavior results - https://onlinelibrary.wiley.com/doi/abs/10.1111/gbb.12379 
A.

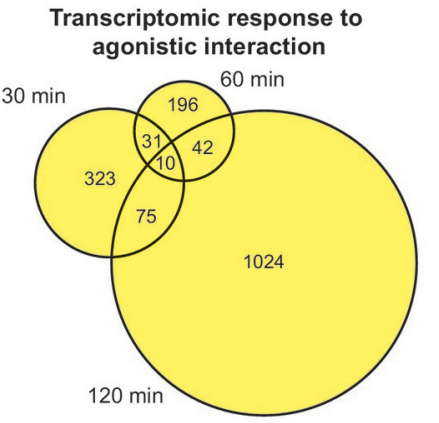

Transcriptomic response to affiliative interaction

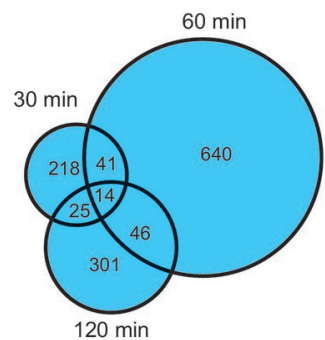

B.

$30 \min$

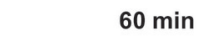

$120 \mathrm{~min}$
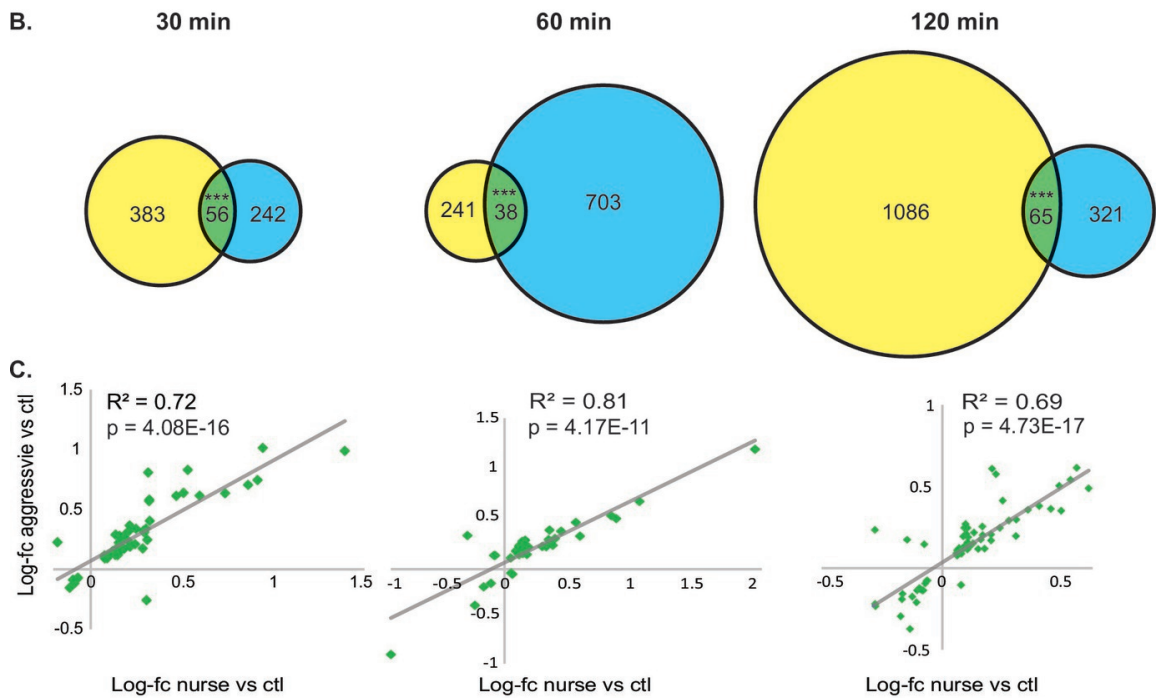

Log-fc nurse vs ctl

D. Genes that respond only in agonistic interaction $30 \mathrm{~min}$

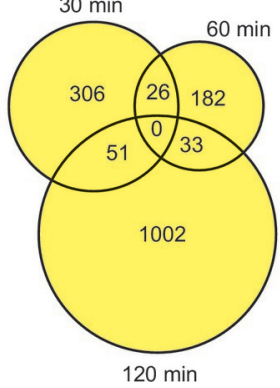

Genes that respond in both social interactions

Genes that respond only in affiliative interaction
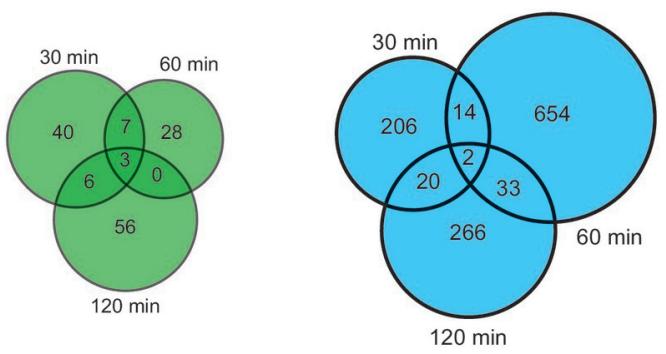

fig1 geneexpression.eps 
A
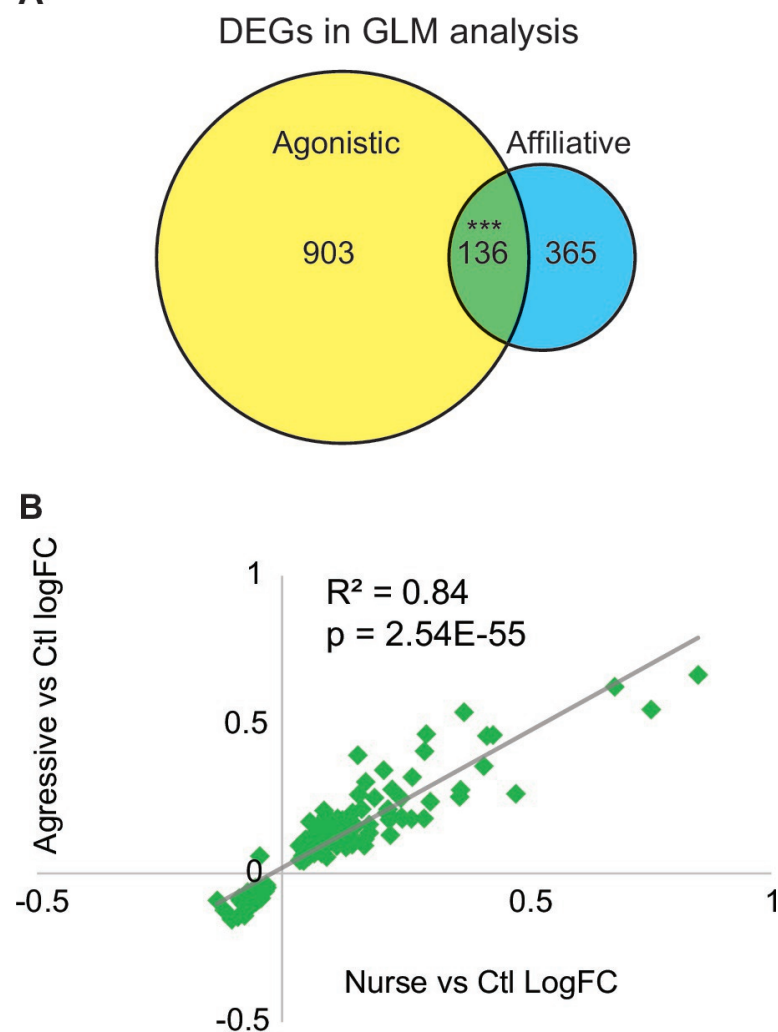

C

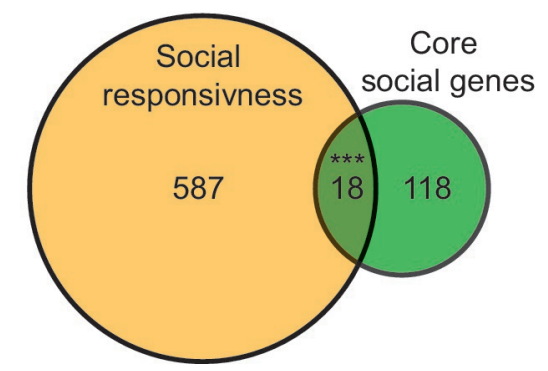

fig2 socialgenes.eps

This article is protected by copyright. All rights reserved. 
A
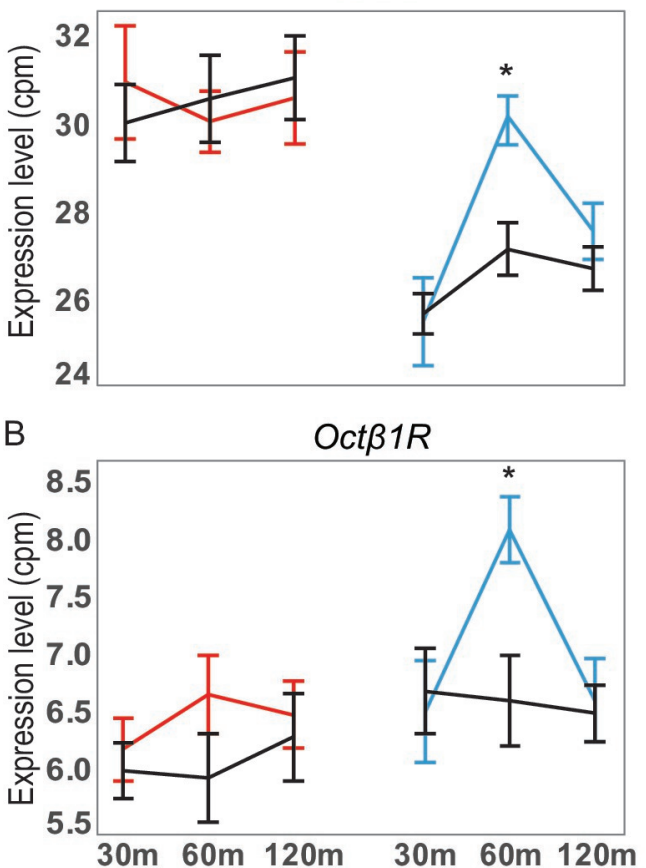

C

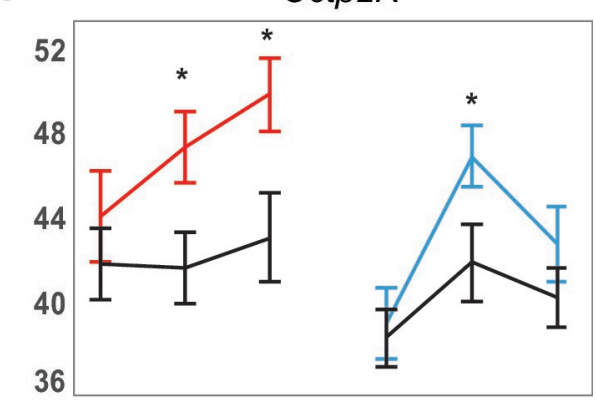

D

fig3 biogenicaminesreceptors.eps

This article is protected by copyright. All rights reserved. 
TFs related to agonistic response

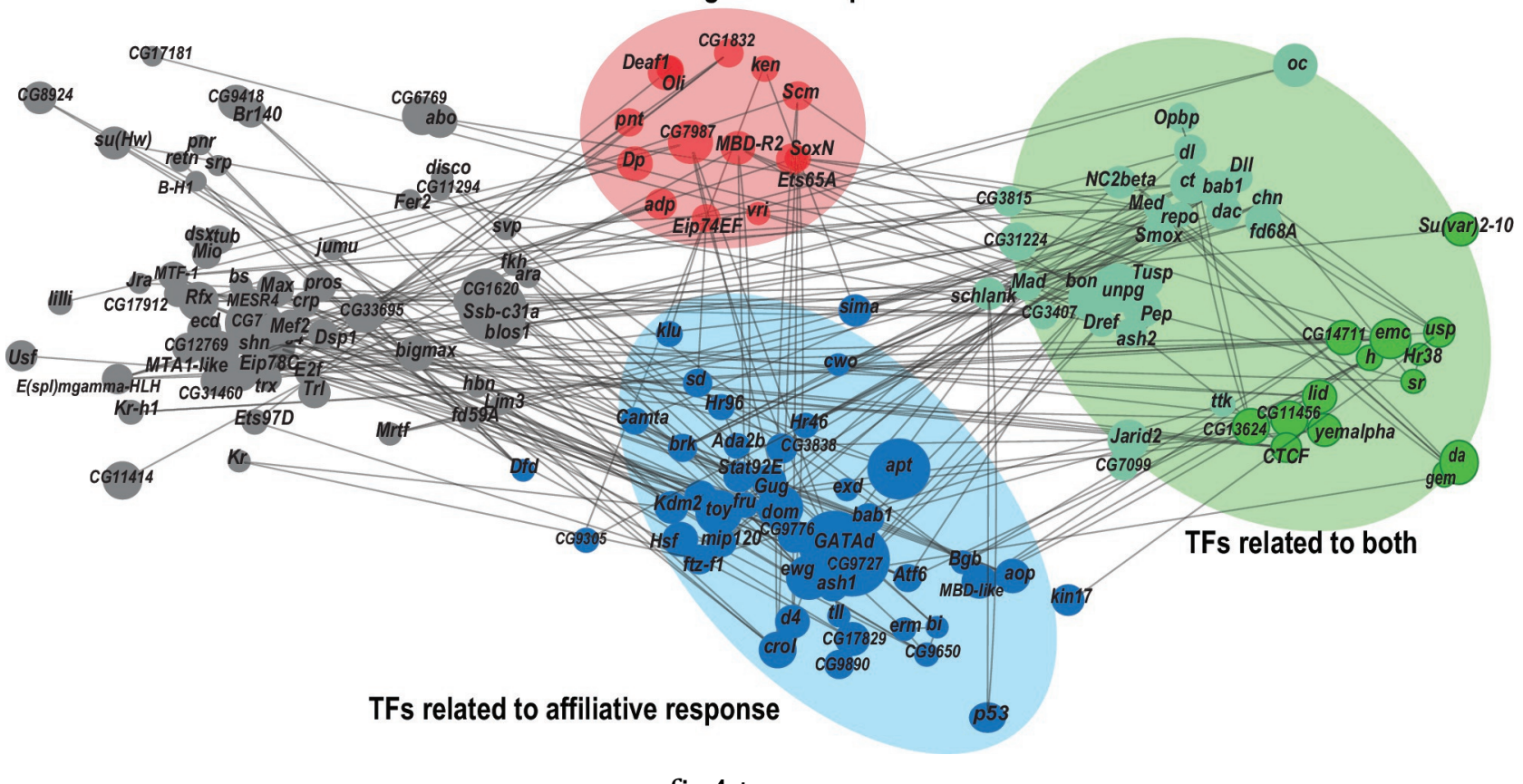

fig4 trn.eps

This article is protected by copyright. All rights reserved. 
A.
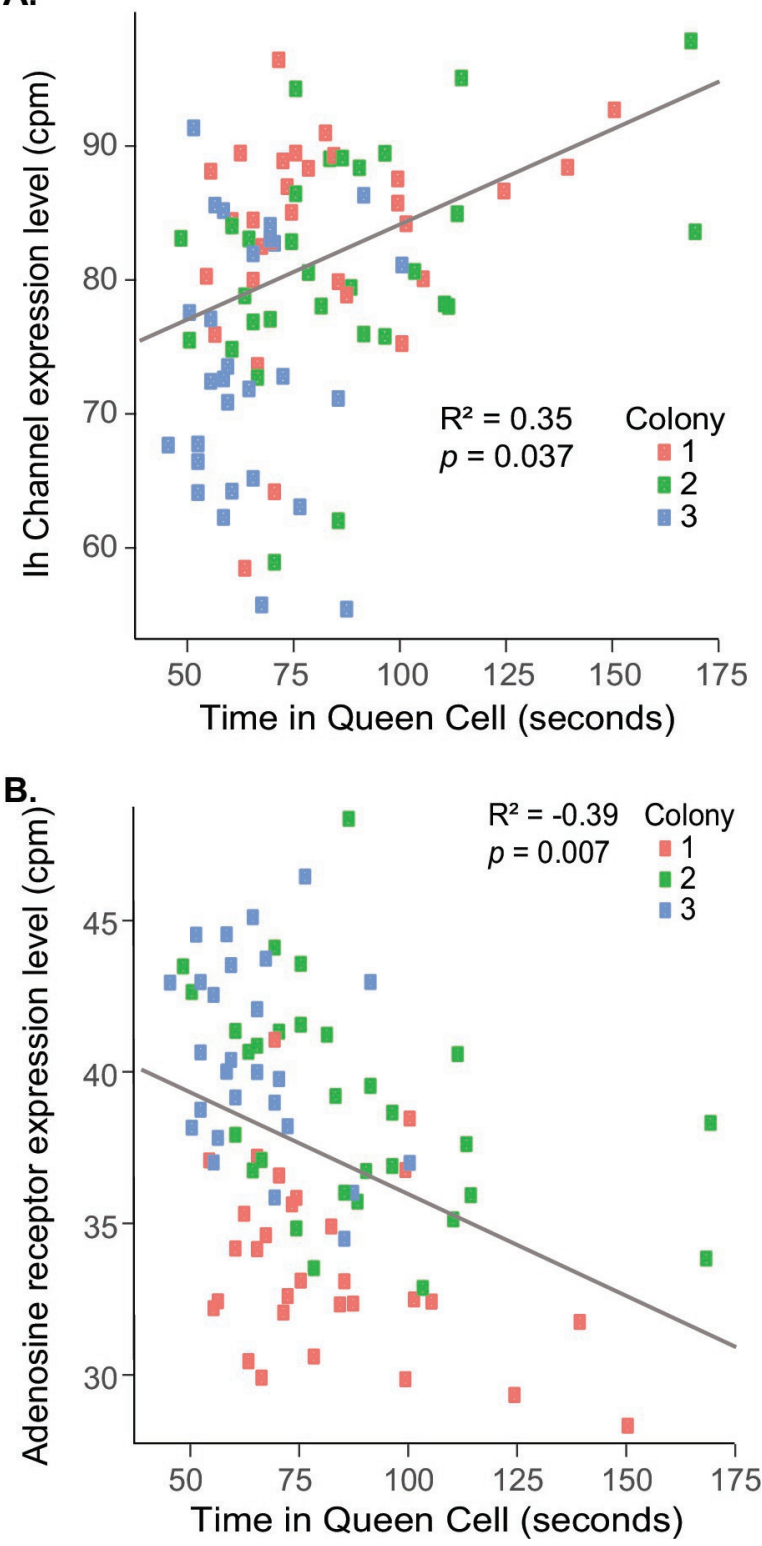

fig5 correlation.eps

This article is protected by copyright. All rights reserved. 
A Q larva / Q larva

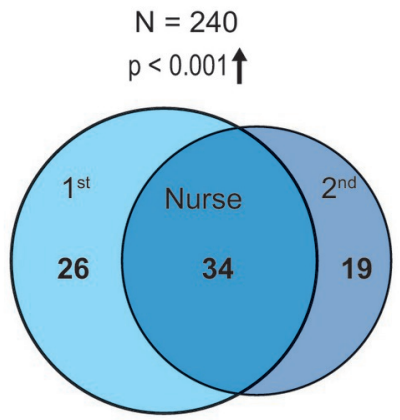

B Intruder / Intruder

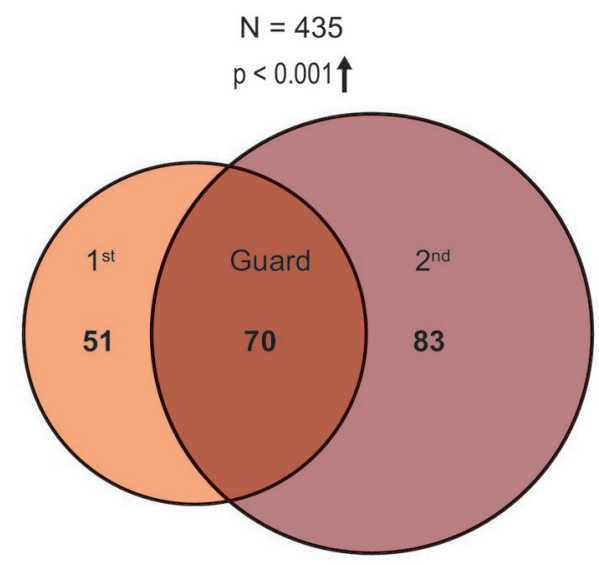

C Q larva / Intruder (random order)

$\mathrm{N}=442$

$p=0.021 \downarrow$

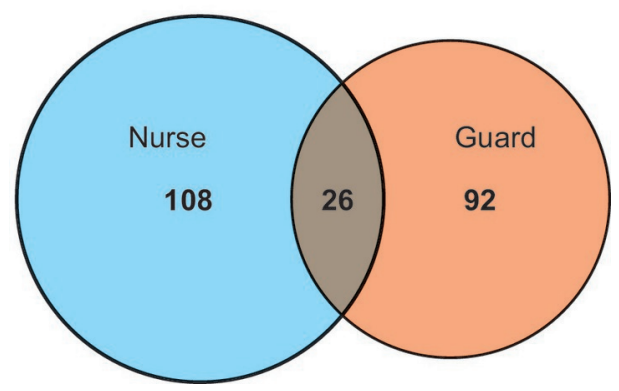

fig6 behavior.eps

This article is protected by copyright. All rights reserved. 
$30 \mathrm{~min}$

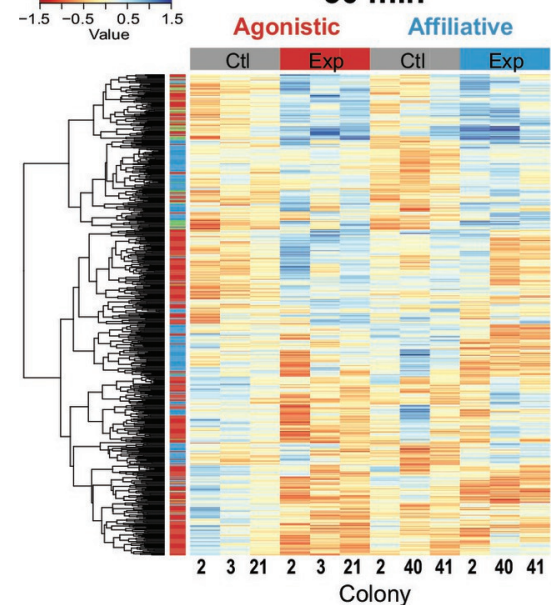

$60 \mathrm{~min}$

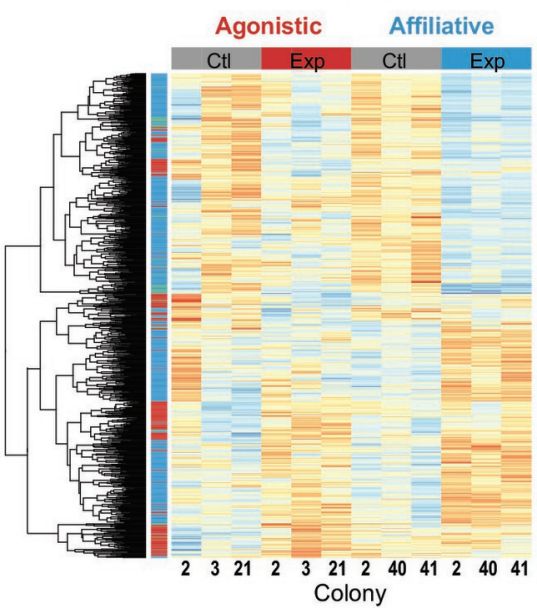

fig s1 heat maps.eps

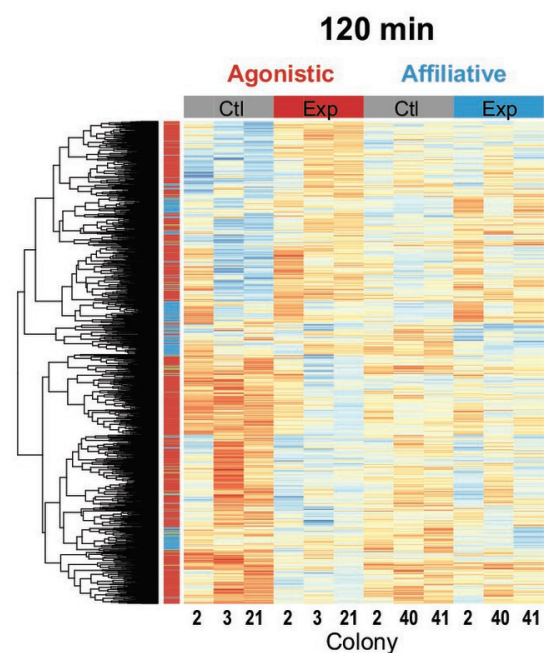

This article is protected by copyright. All rights reserved. 


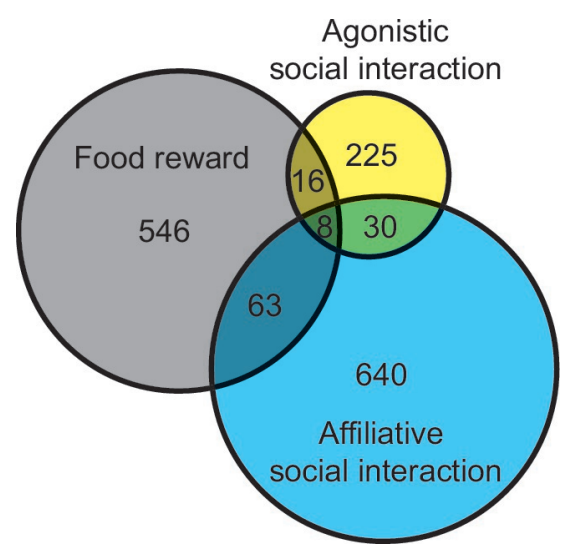

fig s2 food reward.eps

This article is protected by copyright. All rights reserved. 

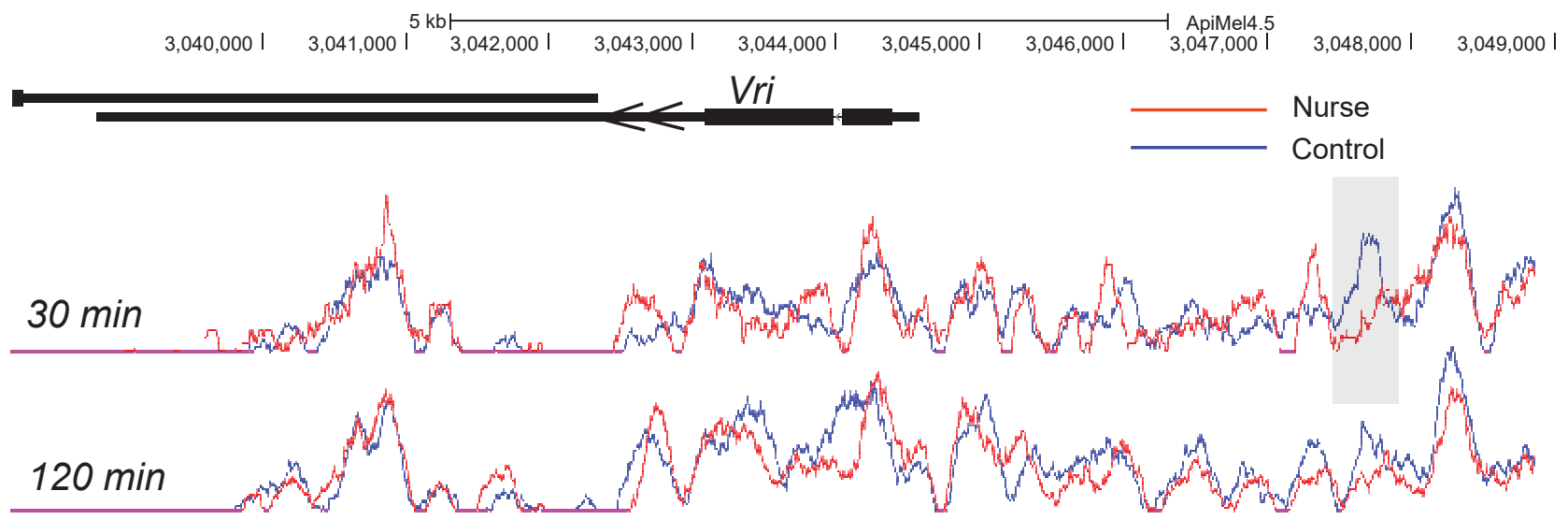
Table 1A

\begin{tabular}{|c|c|c|c|c|c|c|c|c|c|c|}
\hline & \multicolumn{10}{|c|}{ Affiliative interaction } \\
\hline & \multicolumn{4}{|c|}{ Upregulation } & \multirow[b]{2}{*}{$\begin{array}{l}\text { Benjamini } \\
\text { Correction } \\
\end{array}$} & \multicolumn{5}{|c|}{ Downregulation } \\
\hline & GO term & Count & $\begin{array}{c}\text { Fold } \\
\text { Enrichment }\end{array}$ & P-value & & $\mathrm{GO}$ term & Count & $\begin{array}{c}\text { Fold } \\
\text { Enrichment }\end{array}$ & P-value & $\begin{array}{l}\text { Benjamini } \\
\text { Correction } \\
\end{array}$ \\
\hline \multirow{3}{*}{$\begin{array}{l}30 \\
\min \end{array}$} & behavior & 7 & 3.6 & 0.01 & 0.995 & $\begin{array}{l}\text { wing disc } \\
\text { development }\end{array}$ & 5 & 2.9 & 0.08 & 1.00 \\
\hline & $\begin{array}{l}\text { photoreceptor cell } \\
\text { differentiation }\end{array}$ & 5 & 5.4 & 0.01 & 0.957 & nuclease activity & 4 & 6.8 & 0.019 & 0.93 \\
\hline & $\begin{array}{l}\text { regulation of } \\
\text { transcription, DNA- } \\
\text { dependent }\end{array}$ & 8 & 2.3 & 0.04 & 0.998 & & & & & \\
\hline \multirow{8}{*}{$\begin{array}{c}60 \\
\min \end{array}$} & protein folding & 13 & 4.5 & $2 \mathrm{E}-05$ & 0.020 & DNA replication & 8 & 3.5 & 0.007 & 0.99 \\
\hline & $\begin{array}{l}\text { protein localization in } \\
\text { organelle }\end{array}$ & 9 & 3.7 & 0.002 & 0.712 & mitochondrial part & 15 & 1.8 & 0.03 & 0.99 \\
\hline & $\begin{array}{l}\text { sensory organ } \\
\text { development }\end{array}$ & 16 & 1.9 & 0.02 & 0.725 & $\begin{array}{l}\text { DNA replication } \\
\text { (KEGG pathway) }\end{array}$ & 6 & 7.2 & 0.001 & 0.04 \\
\hline & behavior & 14 & 1.9 & 0.03 & 0.689 & & & & & \\
\hline & neuron differentiation & 18 & 1.7 & 0.03 & 0.681 & & & & & \\
\hline & pore complex & 6 & 4.1 & 0.01 & 0.536 & & & & & \\
\hline & axon & 4 & 5.1 & 0.04 & 0.688 & & & & & \\
\hline & amine receptor activity & 3 & 5.6 & 0.09 & 0.847 & & & & & \\
\hline \multirow{3}{*}{$\begin{array}{l}120 \\
\min \end{array}$} & protein folding & 6 & 5.8 & 0.003 & 0.850 & $\begin{array}{l}\text { regulation of small } \\
\text { GTPase mediated } \\
\text { signal transduction }\end{array}$ & 5 & 7.3 & 0.004 & 0.86 \\
\hline & olfactory behavior & 4 & 5.6 & 0.03 & 1.000 & feeding behavior & 3 & 24.1 & 0.006 & 0.78 \\
\hline & metamorphosis & 8 & 2.5 & 0.04 & 0.997 & $\begin{array}{l}\text { response to abiotic } \\
\text { stimulus }\end{array}$ & 4 & 3.6 & 0.09 & 1.00 \\
\hline
\end{tabular}

This article is protected by copyright. All rights reserved. 
Table 1B

\section{$\underline{\text { Agonistic interaction }}$}

\begin{tabular}{|c|c|c|c|c|c|}
\hline \multicolumn{6}{|c|}{ Upregulation } \\
\hline & GO Term & Count & $\begin{array}{c}\text { Fold } \\
\text { Enrichment }\end{array}$ & P-value & $\begin{array}{l}\text { Benjamini } \\
\text { Correction }\end{array}$ \\
\hline \multirow{6}{*}{$\begin{array}{l}30 \\
\min \end{array}$} & $\begin{array}{l}\text { response to organic } \\
\text { substance }\end{array}$ & 6 & 5.7 & 0.003 & 0.683 \\
\hline & cell adhesion & 6 & 3.1 & 0.039 & 0.987 \\
\hline & cognition & 6 & 3.1 & 0.042 & 0.983 \\
\hline & protein folding & 5 & 4.1 & 0.031 & 0.984 \\
\hline & $\begin{array}{l}\text { steroid hormone receptor } \\
\text { activity }\end{array}$ & 3 & 12.9 & 0.021 & 0.983 \\
\hline & $\begin{array}{l}\text { ligand-dependent nuclear } \\
\text { receptor activity }\end{array}$ & 3 & 12.1 & 0.024 & 0.904 \\
\hline \multirow[b]{2}{*}{$\begin{array}{l}60 \\
\min \end{array}$} & $\begin{array}{l}\text { regulation of Ras protein } \\
\text { signal transduction }\end{array}$ & 4 & 6.6 & 0.021 & 0.999 \\
\hline & $\begin{array}{l}\text { regulation of small GTPase } \\
\text { mediated signal transduction }\end{array}$ & 4 & 5.7 & 0.030 & 0.992 \\
\hline \multirow{8}{*}{$\begin{array}{l}120 \\
\min \end{array}$} & chromosome organization & 34 & 2.4 & $2.38 \mathrm{E}-06$ & 0.003 \\
\hline & chromatin organization & 24 & 2.7 & $1.45 \mathrm{E}-05$ & 0.010 \\
\hline & $\begin{array}{l}\text { regulation of gene } \\
\text { expression, epigenetic }\end{array}$ & 15 & 2.6 & 0.001 & 0.219 \\
\hline & $\begin{array}{l}\text { response to organic } \\
\text { substance }\end{array}$ & 10 & 2.1 & 0.050 & 0.764 \\
\hline & response to heat & 7 & 3.1 & 0.023 & 0.659 \\
\hline & histone acetylation & 6 & 6.1 & 0.002 & 0.254 \\
\hline & $\begin{array}{l}\text { transcription regulator } \\
\text { activity }\end{array}$ & 47 & 1.6 & 0.001 & 0.337 \\
\hline & $\begin{array}{l}\text { Notch signaling pathway } \\
\text { (KEGG pathway) }\end{array}$ & 6 & 4.8 & 0.006 & 0.288 \\
\hline
\end{tabular}

\section{Downregulation}

\begin{tabular}{|c|c|c|c|c|}
\hline \multirow[b]{2}{*}{ GO Term } & & \multirow[b]{2}{*}{ P-value } & \multirow[b]{2}{*}{$\begin{array}{l}\text { Benjamini } \\
\text { Correction }\end{array}$} \\
\hline & Count & $\begin{array}{c}\text { Fold } \\
\text { Enrichment }\end{array}$ & & \\
\hline oxidation reduction & 11 & 2.0 & 0.047 & 1.00 \\
\hline contractile fiber & 7 & 26.0 & $9.3 \mathrm{E}-8$ & $1.07 \mathrm{E}-5$ \\
\hline calcium ion binding & 7 & 2.6 & 0.050 & 0.965 \\
\hline
\end{tabular}

\begin{tabular}{|lcccc|}
\hline $\begin{array}{l}\text { actomyosin structure } \\
\text { organization }\end{array}$ & 5 & 18.6 & $1.1 \mathrm{E}-04$ & 0.040 \\
\hline mesoderm development & 6 & 10.7 & $1.8 \mathrm{E}-04$ & 0.022 \\
\hline contractile fiber & 9 & 51.8 & $5.15 \mathrm{E}-13$ & $5.34 \mathrm{E}-11$ \\
\hline $\begin{array}{l}\text { generation of precursor } \\
\text { metabolites and energy }\end{array}$ & 14 & 3.2 & 0.000 & 0.308 \\
\hline pigmentation & 6 & 3.7 & 0.021 & 0.981 \\
\hline lipid particle & 16 & 2.0 & 0.011 & 0.907 \\
\hline $\begin{array}{l}\text { neurotransmitter receptor } \\
\text { activity }\end{array}$ & 6 & 3.8 & 0.019 & 0.508 \\
\hline transcription factor activity & 16 & 1.8 & 0.031 & 0.574 \\
\hline $\begin{array}{l}\text { Oxidative phosphorylation } \\
\text { (KEGG pathway) }\end{array}$ & 9 & 2.8 & 0.012 & 0.252 \\
\hline
\end{tabular}

This article is protected by copyright. All rights reserved. 